White Paper, and this is a marker for the struggle that lies ahead to preserve and develop successful patterns of service against the reforms of the White Paper.

St James's University Hospital, Leeds

\title{
Demography
}

\section{Paul Plant}

Jane Falkingham, Dependency and ageing in Britain: a reexamination of the evidence, Journal of Social Policy, 18, 2 (1989), 2 I I -233 .

There has been growing concern amongst policy makers as to the consequences for public expenditure of the ageing of the British population. Falkingham addresses this concern by looking at the use of indicators of economic dependency by those arguing for the need to reduce the cost of state pension provision in Britain. Her major contribution to the debate is in disentangling whether it was economic or population change that was most influential in determining the overall level of dependency between $195 \mathrm{I}$ and $198 \mathrm{I}$.

The first part of the paper deals with the changing age composition of the British population. Changes in fertility over time are the main determinant of the age structure in populations with low mortality rates, although improvements in mortality at older ages can contribute significantly to the ageing of the elderly population itself. This is illustrated by the use of British data which show the ageing of the population since the turn of the century. During this time the size of the elderly population has risen both relatively - from around $6 \%$ of the population in 1900 to $18 \%$ this decade, and absolutely - from $2.2 \mathrm{~m}$ in I 901 to $9.7 \mathrm{~m}$ in $198 \mathrm{I}$. Britain is also shown to be currently experiencing an ageing of the elderly population itself, with a decrease in the number of young-elderly $\left(60 / 65^{-70}\right)$, combined with an increase in the oldelderly (75 years plus). The proportion of old-elderly is expected to increase until 2030.

The concept of dependency refers to the supposed burden that those not in employment exert on the rest of the economy. An indication of this burden is usually shown by the calculation of dependency ratios. If derived by simply adding the number of people aged $0-19$ years and $60 / 65$ years plus and then dividing this by the number of people aged 20-59/64 years, an increase in the proportion of elderly dependent is simply the direct consequence of the population ageing. Gerontic 
dependency has been increasing from 12 old persons per 100 in the working age ranges in $190 \mathrm{I}$ to 34 in $198 \mathrm{I}$, and is projected to be 38 in $202 \mathrm{I}$. This trend has contributed, it is argued, to the general belief that an ageing population is an economic 'bad', as it is imposing a growing welfare burden on a relatively diminishing working population.

The author argues that it is not necessarily the case that a change in the age profile of a society leads to a change in the burden of dependency. A calculation of dependency based simply on age is inadequate, as it does not take into account labour-force participation rates, particularly by women, or levels of employment in the economy. In the main part of her analysis Falkingham introduces both of these factors into the calculations of dependency ratios for the period 195I-8I. Her results show that overall dependency levels are underestimated when calculated solely on the basis of age, and when disaggregated by sex the ratios were much higher for women than for men. Over the time span considered the women's ratios reflected the increase in the proportion of women working in the formal economy, whilst the rise in unemployment in the 1970 s was highlighted in both the women's and the men's ratios.

Some of the issues surrounding the construction of a female ratio are discussed, given the problems both of measurement and in the interpretation of such ratios. One problem is that only women in paid employment are counted as being economically active, which has the effect of increasing the dependency ratio. It could be argued however that women outside the formal economy reduce overall dependency rather than increase it, as they free their partners of household tasks and, in some cases, relieve the state of its caring responsibilities by looking after old, young or disabled persons. Other issues of interpretation are also discussed, such as the failure of the ratios to take account of the differential social costs of the dependency of the different groups that comprise it.

The time trend in the revised dependency ratios was analysed to see whether it was due to labour market forces or changes in the age structure of the population. To do this the ratio was first standardised for age on the $195^{I}$ age structure. This showed the influence the changing proportion of people in paid employment had had on the ratio. Then the ratio was calculated standardising for $195^{1}$ economic activity rates, to give the effect the changing age structure made to total dependency. When analysing separately the male and female ratios, it was found that changes in the labour market were more important than demographic trends, but when males and females were combined, demographic variations were more important before 1971 . 
Falkingham concludes that these results show the importance of economic activity in the determination of dependency and in so doing they point to the inadequacy of much of the debate on retirement provision. The 1983 Green Paper on the reform of the State Earnings Related Pension Scheme (SERPS) used the argument that future higher dependency levels would be too great for the economy to bear without a reduction in the cost of state pension provision. In failing to acknowledge the importance of economic activity on dependency, policy options other than the reduction in the cost of pensions, such as the scope for increasing employment levels, increasing female labour market participation and encouraging 'guestworkers' into the economy were not considered. The author concludes her paper with a brief discussion of some of these alternatives, acknowledging that there are ethical and practical considerations to be taken into account.

\section{Comment}

This paper offers an interesting analysis of the time trend in Great Britain's dependency ratio between $195 \mathrm{I}$ and $198 \mathrm{I}$. By looking at how changing levels of economic activity have affected it over time, a possible weakness in the argument that there should be a reduction in the cost of state benefit provision, to reduce the burden on the economy of an ageing population, is highlighted. Research such as this shows that, if the worry over dependency levels is well founded, policies designed to increase the level of economic activity also need to be considered.

Department of Community Medicine,

King's College School of Medicine and Dentistry, London

\section{Primary Health Care}

Paul Plant

C. Muller, M. C. Fahs and M. Schechter. Primary medical care for elderly patients, part $\mathrm{I}$ : service mix as seen by an expert panel. Journal of Community Health, 14, 2 ( 1989 ), 79-87.

M. C. Fahs, C. Muller, M. Schechter. Primary medical care for elderly patients, part II : results of a survey of office based clinicians. Journal of Community Health, 14, 2 ( 1989 ), 89-99.

In preparation for a United States national conference on paying physicians for geriatric care held in May 1986, a two-part study of geriatric non-hospital care was carried out. The aim of this research 